\title{
“QUERIDO HOMERO...” \\ O, BRECHAS Y PUENTES ENTRE IMAGINACIÓN Y PODER
}

\author{
Carlos Franz
}

El autor recuerda la famosa querella entre filósofos y poetas formulada por Platón en La República. Al hacerlo, consigna el dictamen platónico contra la intromisión de la poesía y el arte en los asuntos públicos que acaba por expulsar al poeta de la república ideal. Esta brecha entre la imaginación y el poder, que fisuraba la relación entre el mundo de la política y la poesía, se ahonda como un aparente abismo entre las modernas ciencias sociales y el arte. A partir de ese dilema el autor propone varios puentes sobre la brecha, sosteniendo que la imaginación poética no es tan extranjera al pensamiento científico como se piensa; y además, que tanto ella como la emoción —integradas a la razón — podrían contribuir a la racionalidad pública.

Carlos Franz. Escritor. Autor del ensayo La Muralla Enterrada (Planeta, 2001), y de las novelas Santiago Cero y El Lugar Donde Estuvo el Paraíso (Planeta). 
I a discusión o contienda entre el pensamiento humanista y el científico es tan antigua como la pelea entre el hombre y la mujer. Lo demuestra el diálogo platónico que comento en este ensayo.

Sus ramificaciones y analogías son inmensas. Hay quienes sostienen que el atraso de los países del Tercer Mundo puede explicarse simplemente por una resistencia nuestra al método científico, determinada por ataduras culturales que privilegian aproximaciones intuitivas, sentimentales cuando no religiosas y, por ende, poéticas, a la realidad.

En el corazón de las sociedades más avanzadas, la guerra de los sexos, y la discusión de género, tan de moda en la academia, también incluye, a menudo, una supuesta división del trabajo "cerebral": los hombres tenderían a poseer habilidades matemáticas (la herramienta, si no la sustancia misma, del pensamiento científico), en tanto las mujeres poseerían habilidades verbales (la sustancia misma del pensamiento analógico, si no poético.) Esto habría determinado la monopolización del poder técnico en manos de los hombres; $y$, en una época dominada por la técnica...

Que esta diferente aproximación a las circunstancias de la realidad implica un conflicto constante lo testimonian las disciplinas que también sufren - muchas veces sin saberlo o llamarlo de este modo- de este dilema. Desde la sicología — por mencionar la más blanda de las ciencias - a la economía - por mencionar a la más dura de las artes- observan, también, las inadecuaciones entre la aproximación científica, práctica u 'objetiva', a la realidad; versus la aproximación intuitiva, emocional o subjetiva, a la misma.

La discusión más rica se da precisamente donde hay más poder envuelto. La economía, como recién admitida —y no del todo— al club de las ciencias duras, es acusada de privilegiar un cientifismo ramplón, hijo del más puro utilitarismo — del tipo costo beneficio benthamiano_- en la toma de decisiones públicas y privadas que por su complejidad no debieran hacerse —afirman los críticos — sin el auxilio de 'instrumentos' más delicados como son la intuición emotiva y la imaginación poética. Científicos muchísimo más duros, como los físicos, están dispuestos a reconocerle ese papel a la imaginación. ¿Por qué no la ciencia social hegemónica de nuestros días? (En aras de la verdad, los economistas inteligentes —que también los hay - ya no sólo lo reconocen sino que lo practican.)

En este ensayo me ocupo de esa discusión en los términos de la querella ya clásica entre poetas y filósofos. Y al final propongo algunos puentes sobre esa brecha polémica. Quizá no esté de más aclarar que estos puentes son metafóricos igual que la brecha misma. Puesto que vivimos en 
la brecha nosotros mismos somos el puente. Todos somos, en diferentes momentos del día y de nuestras vidas, y casi siempre simultáneamente, artistas y economistas, poetas y filósofos.

\section{La querella de los filósofos y los poetas}

En la V parte de su diálogo sobre la Repúblicaㄹ, Platón argumenta su famosa "Querella entre la filosofía y la poesía". Y la resuelve — como se sabe- a favor de los filósofos (entendiendo por tales, en sentido amplio: los hombres racionales y virtuosos, capaces de calcular en interés general.) Luego de criticar la distancia que separa al arte de la realidad, diciendo que "la poesía y los poetas son terceros en la sucesión al trono de la Verdad"2 - o sea, que el arte es sólo una imagen de la naturaleza, que a su vez es sólo una imagen de la idea-, Platón pasa a atacar el rol de la poesía y del arte juzgándolos nocivos en la educación, la política, y en general en los asuntos públicos.

Para remachar sus argumentos contra la poesía —en el pasaje, a mi juicio, más dramático (y divertido) de su ataque-, Platón pone en el banquillo nada menos que al mayor poeta de la antigüedad, Homero. Y le encarga a Sócrates formularle una pregunta de la cual dependerá el juicio de generaciones sobre el rol de la poesía en los asuntos públicos:

"Querido Homero - dice Platón por boca de Sócrates (esta familiaridad entre gigantes es deliciosa)—, querido Homero, quisiéramos preguntarte, hemos definido al artista como uno que produce imágenes a una triple distancia de la realidad. Si fuera efectivo que tu conocimiento de la excelencia humana es tal que pudiera elevarte al segundo rango [o sea, a aquel de la naturaleza], y si fuera cierto que tú pudieras realmente decir cuáles conductas harían superiores a los hombres, ya sea como individuos o como ciudadanos, ¿podrías nombrar un país cualquiera que haya sido mejor gobernado gracias a tus esfuerzos?"3.

El pobre Homero no respondió. No respondió, como propondré más adelante, no sólo porque llevaba muerto unos quinientos años, sino porque el vate ciego vio claramente - ya que vate también significa vidente- que la pregunta era capciosa, que en ese juicio imaginario se había pasado sentencia en su contra mucho antes, y que su suerte estaba echada.

\footnotetext{
${ }^{1}$ Plato, The Republic. Todas las citas están tomadas de la edición de Oxford University Press, 1942. La traducción al castellano es mía.

${ }^{2}$ Ibídem, XXXV, p. 320.

${ }^{3}$ Ibídem, XXXV, p. 322.
} 
En efecto, Platón sólo esperaba ese silencio para confirmar el decreto de expulsión del poeta de la República, que ya había formulado antes en su tratado. Así reza la condena platónica milenaria de los filósofos contra los poetas:

Si aparece en nuestra ciudad un poeta..., "nos inclinaremos ante un ser dotado de tan milagrosas capacidades para dar placer; pero le diremos que no podemos permitirnos admitir tal clase de persona en nuestra comunidad; lo coronaremos con una vincha de lana; untaremos su frente con mirra; y lo conduciremos a las fronteras de algún otro país"4.

Confieso que, en mi fuero interno y en momentos de desaliento, digamos gremial, yo mismo me he sentido muchas veces tentado de expulsar a algunos poetas, o aplicarles condenas todavía más fuertes: decapitación, desmembramiento, hoguera... Platón tenía buenas razones para expulsar al poeta, me digo, por experiencia propia. Pero entonces me acuerdo de que yo también he sido poeta — aunque malo—y me dan ganas de contestarle a Platón.

El objetivo de ensayar estos comentarios, consiste en esbozar esa respuesta a la pregunta retórica que Sócrates formuló hace 2.300 años a la poesía, en la persona de Homero. Para hacerlo, partiré por recordar sumariamente las objeciones platónicas a la intromisión de la poesía y el arte en los asuntos públicos.

Enseguida, demostraré que Platón tenía y sigue teniendo —en sus propios términos - toda la razón, si nos atenemos a la obra de unos cuantos novelistas contemporáneos.

Y luego, en una segunda parte, imaginaré una posible respuesta de Homero basada en una interpretación diferente de las objeciones de su acusador platónico. Al hacerlo, sugeriré que la imaginación poética no es tan extranjera al pensamiento científico, como se piensa; y además, que tanto ella, como la emoción —integradas a la razón- podrían contribuir a la racionalidad pública.

\section{La pregunta de Platón, o la brecha}

Desde que Platón expulsa al poeta de su República, por no responderle su preguntita, sospechamos que entre la literatura y el arte, por un lado, y la racionalidad política, por el otro, hay una brecha. ¿De qué ancho y fondo?, imagino que se preguntarán los ingenieros sociales. Para responderles sondeemos un poco esa brecha, de la mano de Platón.

\footnotetext{
${ }^{4}$ Ibídem, IX, 2, p. 83.
} 
En primer lugar, según Platón, el arte es una imagen de una imagen; o sea, el arte emplea lo que para estos efectos llamaré “imaginación”. Esta objeción al arte es de una crudeza epistemológica divertida, pero lo que en realidad me gusta de ella es que Platón no se anda con eufemismos al señalar la profundidad de la brecha: los poetas —en su pretensión ancestral de imaginar 'lo otro' - hablan de lo que no saben. Homero se mete en los asuntos de Estado, en la conducción de la guerra, y en la voluntad de los dioses, sin ser ningún estadista, ni un guerrero, ni un teólogo o filósofo.

Cualquiera que haya intentado preparar un caldillo de congrio con la receta que da Neruda en su oda, sabrá que el poeta glotón nunca entró a la cocina.

¿Será necesario vivir mucho y practicar diversos oficios para escribir, Pepe?, le pregunté una vez a José Donoso. Y él me contestó: "Nooo, pamplinas, basta con la hiperestesia del escritor." Tuve que acudir al diccionario: hiperestesia, la hipersensibilidad del artista. (Platón lo habría coronado de inmediato con una vincha, y lo habría mandado a la frontera.)

Esta objeción pone en entredicho la piedra angular del mito poético, la capacidad visionaria de la inspiración.

La segunda objeción filosófica al arte — que ahonda la brecha-, es que el poeta habla desde las emociones. Además de que la emoción ocupa un lugar estructuralmente inferior en el sistema del alma platónica, la emotividad en el arte implica — para Platón — dos fallas graves, primero, distorsiona la razón del espectador, principalmente porque al invitarnos a experimentar miedo, pena, amor, etc., hace lo contrario de aquello que la razón analítica debe hacer para ser objetiva, que es distanciarnos de esas emociones; y segundo, el arte corrompe la virtud, pues presenta al hombre como un ser débil, sujeto de sus pasiones, en tanto que el hombre virtuoso es quien las domina. Las domina tanto que no puede ser dañado, como Sócrates que no siente miedo, ni siquiera amor hacia la propia vida, cuando bebe dignamente la cicuta.

Por el contrario, en la Orestíada, el ciclo trágico de Esquilo inspirado en los poemas homéricos, Clitemnestra le pone los cuernos al ingenuo de Agamenón y luego lo asesina; Orestes no puede sino vengar a su padre, asesinando a su madre; y luego, perseguido por las furias del remordimiento, se come un dedo... Si a alguien le parece que estas son exageraciones de tragedias antiguas, los invito a recordar la teleserie Machos, en donde lo "macho" contemporáneo consiste en ser una víctima indefensa de la propia pasión, y de las maniobras de las mujeres.

Finalmente -y por resumir, ya que las objeciones de Platón son más numerosas-, el cargo más grave contra la poesía, formulado en el 
capítulo IX de La República, dedicado a la censura literaria, es que el poeta "falsea la naturaleza de los dioses y de los héroes" calumnia a lo divino, y duda de la grandeza de lo humano. "La naturaleza es buena y debe ser representada de ese modo"'. Y en cuanto al más allá: "Los poetas deben ser instruidos para que hablen bien del otro mundo"?

Después de estas demoledoras objeciones contra la poesía, Platón concluye por donde había empezado, cito: "hay una larga y antigua querella entre poesía y filosofía, hay muchas pruebas de ello..." ${ }^{8}$, dice. Y a continuación transcribe algunas enigmáticas líneas de textos literarios donde poetas insolentes habrían atacado a la filosofía y al pensamiento racional. Graciosamente, mi edición Oxford comentada, informa al lector, en una nota al pie de página, que todas esas citas que hace Platón corresponden a obras que se han perdido, y cuyos autores se ignoran. (Tiene gracia ese breve párrafo, que apenas consigna tres líneas sueltas, pues además sugiere que Platón respiraba por la herida, que su expulsión del poeta dista de ser la respuesta mesurada del filósofo virtuoso, y huele a la venganza de un ofendido. Pero dejemos esto de lado...)

Como se comprenderá, esa fue una tentación demasiado fuerte para un novelista. Por divertirme, y al azar de mi memoria, me puse a completar la lista platónica perdida con algunos ejemplos de obras literarias que demuestran que Platón tenía, y sigue teniendo, toda la razón del mundo. Los escritores empleamos una imaginación arbitraria; estimulamos e incluso preferimos la emoción a la razón; y sí, insultamos a los dioses más caros a cada época.

Recordé, por ejemplo, La Montaña Mágica, de Thomas Mann. Como sabemos, el joven ingeniero naval Hans Castorp, modelo de sana inteligencia pragmática, sube a una montaña como esta para visitar a un amigo enfermo de tuberculosis, y poco a poco la enfermedad lo va seduciendo y reteniendo en el sanatorio. Contra el telón de fondo de la discusión intelectual entre dos pacientes, Naphta y Settembrini, el jesuita y el librepensador, Hans Castorp —o más bien algo de Hans que Hans no sabía tener, quizá su aspecto dionisiaco-, escoge la enfermedad como finura y goce del espíritu. Esto se ve claro en la extraordinaria escena de la tormenta de nieve..., pero no tengo espacio para demostrarlo. Sólo quisiera proponer, con este ejemplo tomado de la obra de uno de los novelistas más filosóficos que es dable imaginar, ¡cuán acertado estaba Platón! Esa crítica

\footnotetext{
${ }^{5}$ Ibídem, IX, p. 67.

${ }^{6}$ Ibídem, IX, p. 69.

${ }^{7}$ Ibídem, IX, p. 74.

${ }^{8}$ Ibídem, XXXVII, p. 331.
} 
implícita a la normalidad, ese desdén de la salud, esa exaltación de lo morboso, no pueden menos que resultar perturbadores, o francamente delictuosos, para un espíritu científico. Todo el plan AUGE podría quedar en entredicho si admitiéramos seriamente a este enfermo que no sólo prefiere y goza el bacilo - lo que pasa con muchos adictos - sino que crece y se refina y se humaniza con la enfermedad.

Para que no se me acuse de buscar ejemplos sólo en extranjeros decadentes, como Thomas Mann, podría citar también la saludable tradición del realismo nacional. Otra obra que yo agregaría a la larga lista perdida de ofensas de la poesía contra la razón, podría ser El Roto de Joaquín Edwards Bello. Esmeraldo, su protagonista, es presentado por Edwards Bello como una ilustración de los cuadros estadísticos de pobreza incluidos en la misma novela. Nacido en un prostíbulo detrás de la Estación Central, delincuente desde la niñez, presidiario apenas tuvo edad, Esmeraldo es sujeto de un audaz proyecto de reforma social auspiciado por la prensa de la época para acabar con el crimen (cualquier coincidencia con Paz Ciudadana es indudable premonición poética). Incluso, el periodista que promueve esa campaña de bien público se lleva a Esmeraldo a vivir a su casa, y mientras tanto, para erradicar el mal de raíz, la municipalidad demuele los prostíbulos de la calle Borja, foco del mal, para hacer casitas sociales. Hasta aquí la novela no puede ser más edificante - Platón habría estado feliz - pero en el final, la traidora poesía suplanta incluso las buenas intenciones del autor. Cuando vuelve a su barrio y lo ve arrasado, a Esmeraldo lo arrebata una furia instintiva, y apuñala a su benefactor, para luego perderse corriendo por las líneas ferroviarias, tras la Estación. Oscuramente perplejos, maliciamos que el bandido reformado amaba su barrio, amaba el lugar que lo había hecho un criminal, esa miseria era su hogar.

Podría seguir ad aeternum - pero sólo déjenme agregar a la lista perdida de Platón, Guerra y Paz, de Tolstoi. No se preocupen que no se las voy a contar, sólo quisiera recordarles la tesis de la historia que Tolstoi argumenta e ilustra en su gran novela. Ni Napoleón, ni el zar Alejandro, saben lo que hacen. Ellos creen que conducen una guerra, pero apenas agregan confusión a la deriva ininteligible de los hechos. El mariscal Kutuzov, viejo, medio ciego, sentimental, es el más sabio, pero no porque sepa lo que hace, al contrario, porque no trata de influir, sino más bien - cómo lo dijéramos-, de no estorbar, en lo que debe ocurrir. No tengo la menor intención de defender la tesis histórica de Tolstoi, aunque mi corazoncito de escritor late con ella (por otra parte, el brillante análisis que le dedicó Isaiah Berlin, me releva de insistir en su importancia). Lo que acá me interesa proponer es que la actitud del Tolstoi artista le da plenamente la 
razón a Platón. El poeta difama a los héroes y a los dioses: no sólo el hombre no es dueño de su destino, ni siquiera los conductores de hombres conducen algo, y el azar se nos presenta como necesidad. Tolstoi blasfema contra la voluntad racional de influir en la historia humana de un modo - y esta palabra es crucial- decisivo. Si "el rey es esclavo de la historia", como dice el narrador en esta novela, ¿qué quedará para los diseñadores y gestores de políticas públicas?

Cada una de las tres novelas anteriores podría ser agregada a la lista de ofensas de la poesía contra la filosofía —o razón científica- y sus autores merecerían, ipso facto, la vincha, la mirra, y ser deportados hacia la frontera. Thomas Mann imagina lo que no es posible —o quizá admisible- saber, que pudiera ser "más humano" estar enfermo; Edwards Bello, a pesar de sus intenciones de denuncia social, termina sugiriendo "el derecho" de su personaje a la miseria y el crimen; Tolstoi "calumnia" a los héroes y los dioses mostrándolos impotentes por igual.

Antes de pasar a la posible respuesta de Homero a estas objeciones, quisiera salirles al paso a dos inquietudes posibles. Esa desconfianza platónica hacia el arte ¿no será un prejuicio arcaico que nosotros, la elite culta y posmoderna, por supuesto no compartimos - y que si compartiéramos no lo confesaríamos? A mi juicio $-\mathrm{y}$ podemos discutirlo, ya que procedo como poeta, sin la evidencia empírica de una encuesta- la relación entre filosofía, ciencia, y razón, por un lado; y poesía, arte, e imaginación, por el otro, no ha cambiado, en lo sustancial, desde que Platón describiera esta querella. Para decirlo con Perogrullo, el arte sigue siendo inofensivo, hasta que ofende nuestras creencias o axiomas. Hasta que decidimos tomarlo en serio, o hasta que él juega con nuestros asuntos más serios.

La otra objeción la llamaré — por puro animus giocandi, o ganas de joder-, el gambito del Estagirita. En efecto, conforme a la más pura dialéctica, después del ataque de los poetas a la filosofía y de la respuesta de la filosofía con el exilio de los poetas decretado por Platón, Aristóteles formula esa conocida síntesis que debiera dejarnos a todos contentos. Recordémosla: nada de expulsar al poeta, pero nada tampoco de reconocerle algún papel orientador del orden social. En cambio, el estagirita admite el desorden del arte en el orden de la república — de ahí el gambito- asignándole una función. El arte y la poesía, como bien sabemos, sirven a la sociedad mediante la catarsis que provocan sus obras. Hasta la tragedia - la más peligrosa de las formas poéticas - se transforma así en una especie de purificación individual y colectiva, donde vivimos imaginaria, vicariamente, aquellos impulsos e ideas prohibidas o nocivas que sería demasiado peligroso practicar o admitir en el espacio de la razón y la acción. No 
tengo espacio, ni capacidad, para trazar la ilustre descendencia de esta noción, hasta el utilitarismo freudiano de la ensoñación artística como desahogo. Pero, mi incomodidad con ese bienintencionado gambito aristotélico siempre la ha agravado el hecho de que la palabra catarsis, en griego, significa literalmente "purgación". Con lo que los artistas y los poetas venimos a ser algo así como un purgante social. ¡La poesía contra la estitiquez!

A pesar de ello, las breves ideas que expondré a continuación —al esbozar una posible respuesta de Homero a la pregunta capciosa de Platón-, me temo que constituyen una versión bastante modificada, pero que aún participa, en mucho, de esa repugnante noción aristotélica — repugnante, también, porque domestica a los poetas, privándonos, en cierta medida, de nuestra querida aura de misterio, pecado y peligro.

\section{La respuesta de Homero, o un puente sobre la brecha}

"Querido Homero, ¿podrías nombrar un país cualquiera que haya sido mejor gobernado gracias a tus esfuerzos?"

¿Qué puede responder el pobre Homero? Antes que nada, quisiera advertir que la respuesta que imaginaré implica una paradoja inquietante para mí, una que quizás envuelve hasta una traición a Homero: los poetas no están obligados a dar respuestas. Su privilegio ancestral es el de hacer preguntas incómodas u oscuras, a menudo en forma de acertijos, no andar resolviéndolos. El oscuro Hölderlin, me parece que percibe esto cuando dice: "El hombre es un dios cuando sueña, y un mendigo cuando reflexiona". De modo que todo lo que Homero reflexione — por mi boca-, además de apócrifo, debe entenderse como menos significativo que sus evasivas de siglos ante la pregunta de Platón, o sus enigmáticos sueños, o sus ofensivas sinrazones.

A pesar de ello, quisiera consignar dos aspectos en los cuales vislumbro un posible puente sobre la brecha que Platón vio entre poetas y filósofos.

En primer lugar, la imaginación poética, esa capacidad de intuir una imagen de la verdad, sin conocerla, podría no ser tan ajena al método científico, como suele creerse. En su Lógica del Descubrimiento Científi$c o^{9}$, Karl Popper señala que, en la etapa crucial de la construcción de hipótesis científicas, y sobre todo en la creación de aquellas hipótesis más fructíferas (o falsificables), la mente no se comporta como una obediente

\footnotetext{
${ }^{9}$ Popper, Karl: The Logic of Scientific Discovery, 1980.
} 
amanuense de la evidencia empírica, sino que, saltándose el proceso inductivo, intuye la hipótesis, mediante un acto que envuelve, casi, un arrebato poético. Es decir, al menos en esta etapa crucial, el científico también mantiene tratos con esa loca de la casa que es la imaginación. Dice Popper: "No hay tal cosa como un método lógico para tener nuevas ideas, o una reconstrucción lógica de ese proceso. Mi visión puede expresarse diciendo que cada nuevo descubrimiento contiene un elemento irracional, o una intuición creativa en el sentido de Bergson" 10 .

Esa salida del riguroso camino de la inducción, tomando por el atajo de la "intuición creativa", me suena muy familiar a la imaginación poética. Hay un momento en la creación literaria - y los escritores lo corroborarán o negarán-, cuando las palabras, y no las ideas —si se me permite esta distinción poética一, guían la mano. Algo en el sonido y en la imagen de una palabra se asocia espontáneamente con el sonido y la imagen de otra, y entonces mandamos al diablo el plan, la hipótesis previa es abandonada, como una señora aburrida, y nos escapamos por la ventana con esa loca intuitiva. "Éramos tan arrebatados en la guerra/ que jamás actuábamos de acuerdo a un plan" 11 , canta en su "Ars Vitae" el poeta Diego Maquieira. Pero si mis lectores filosóficos juzgan que, en este punto, debiera dar ejemplos de mentes científicas y no de poetas arrebatados, déjenme cederle la palabra a Einstein: "Los conceptos físicos son invenciones libres del espíritu humano, y no son, contra lo que pueda parecer, determinados únicamente por el mundo externo"12. O bien, esta otra idea einsteniana citada por el mismo Popper, en abono de su tesis: "La búsqueda de esas leyes altamente universales (...) mediante las cuales una imagen del mundo puede obtenerse por pura deducción. No hay un sendero lógico que conduzca a tales leyes —escribe Einstein-, ellas sólo pueden alcanzarse por intuición, basada en algo como un 'amor intelectual' (Einfuhlung) hacia los objetos de la experiencia"13.

'Invenciones libres', 'un amor intelectual...', si esto no es poesía... Con todo, no dejo de ver que esta posible similitud entre el procedimiento poético y el científico, en caso de ser válida, acaba precisamente en la hipótesis. Allí donde el científico empieza el arduo proceso de la experimentación y verificación (o falsificación) empírica, allí mismo es donde el poeta se echa de guata al sol a disfrutar de la verdad instantánea de su imagen. Pero esta objeción no basta para negar, a mi juicio, que la lectura

\footnotetext{
${ }^{10}$ Popper, Karl: The Logic of Scientific Discovery, 1980, p. 32.

${ }^{11}$ Maquieira, Diego: "Ars Vitae", p. 112.

${ }^{12}$ Einstein, Albert y Leopold Infeld: The Evolution of Physics, 1938, p. 31.

${ }^{13}$ Popper, Karl: The Logic of Scientific Discovery, 1980.
} 
de poesía y prosa literaria podría estimular más que un poco esos arrebatos intuitivos que, también en la mente científica y filosófica, parecen estar conectados a las más fructíferas hipótesis.

Tenemos, entonces, una tabla de ese posible puente sobre la brecha entre poesía y filosofía. Un aspecto de la posible respuesta de Homero a la pregunta capciosa de Platón.

La otra tabla que se me ocurre poner, en este posible puente sobre la brecha, responde a la segunda objeción platónica: la emoción que el artista emplea como recurso expresivo y que el poeta estimula en los espectadores o lectores. Esta emoción no sólo distorsiona la razón; también podríamos decir que la emoción producida por la obra literaria, al hacernos experimentar sentimientos muy vívidamente, pero a distancia, ya que no son nuestros, estimula y motiva a la razón a imaginar la experiencia de lo ajeno. Y de ese modo, una emoción razonada (si se me permite el oximoron), podría ser una herramienta útil en el diseño, decisión y gestión de asuntos públicos, tan variados como los que acá se han debatido.

Martha Nussbaum, en su interesante ensayo Justicia Poética ${ }^{14}$, que trata precisamente de una posible contribución de la imaginación literaria a la vida pública, desarrolla esa idea mucho mejor de lo que puedo hacer yo. Por ahora, sólo mencionaré sucintamente su argumento de que un mecanismo de lectura literaria básico, como la identificación (o sea, la capacidad de vivir imaginariamente experiencias ajenas), puede contribuir a una descripción más compleja y justa de problemas públicos que, a menudo, porque se juzga parcial particularizarlos, se tratan de un modo tan genérico que nadie puede reconocerse ni en la descripción del problema, ni en las soluciones propuestas. Por su parte, esa suerte de compasión distanciada que la poesía y la novela estimulan en sus lectores (o sea, la capacidad de vivir sentimientos tan ajenos, que hasta son imaginarios, como si fueran propios) podría ser relevante en la toma de decisiones complejas, especialmente cuando hay envueltos valores cuya interpretación es tan dispersa y plural que ninguna encuesta podría válidamente sintetizarla. Y enriquecer de ese modo las perspectivas más crudamente utilitaristas del costo-beneficio.

Desde los derechos de las minorías que por definición les corresponde concordar también a quienes no son parte de esas minorías, hasta la definición de lo que debemos entender por bienestar, podrían beneficiarse de la lectura y quizá hasta de esta práctica poética.

\footnotetext{
${ }^{14}$ Nussbaum, Martha: Poetic Justice: The Literary Imagination and Public Life,
} 1995. 
Por ejemplo, los estudios económico-estadísticos sobre felicidad comparativa entre países podrían enriquecerse tanto en su diseño como en su interpretación, con la lectura atenta de Mann, cuando valoriza la enfermedad, o de Edwards Bello, cuando problematiza lo miserable. ¿Cómo pudiéramos hacer más complejo el paradigma económico de bienestar, y el de felicidad individual para abarcar estas difíciles nociones? La entera discusión acerca de los roles de liderazgo y conducción social — que implica también la de los límites de la intervención o regulación estatal de lo privado-, podría beneficiarse de la corrosiva "experiencia imaginaria" que propone al lector Guerra y Paz, de Tolstoi. Invitar a nuestros líderes y asesores de líderes a perderse con Pëtr Bezujov en la batalla de Borodino -batalla que nadie dirige, que nadie puede explicar, y que nadie sabe siquiera dónde está ocurriendo, exactamente-, podría ser una experiencia imaginaria de benéfica humildad para quienes aspiran a guiarnos en las guerras y las batallas de los asuntos públicos.

Quizás, al terminar, no esté de más aclarar que mi objetivo, al proponer un lugar para la imaginación y la emoción literarias en la vida pública (al proponerla como un posible puente sobre la brecha), no consiste en reemplazar el pensamiento científico y filosófico, por el poético, sino en señalar donde podría haber oportunidades para un rol fecundo del arte en la cosa pública, que salve la disyuntiva usual y simplista de Platón, la que entiende como provocación toda poesía que no sea pura ornamentación.

Alguien reprochará que esto implica un presente griego, y una asimetría: introducir el caballo de la imaginación poética en la ciudadela de la razón pública tiende a poetizar la filosofía, y no a la inversa. Así es, lo reconozco, y aventuro una justificación. Como ya lo he dicho, Platón estaba en lo cierto, no se puede confiar en los poetas cuando se trata de decidir la guerra o manejar la hacienda pública (en realidad, tengo amigos poetas en los cuales no se puede confiar ni siquiera cuando manejan el auto). Pero otro tanto se puede decir de ciertos economistas distraídos que conozco. Quiero decir que los filósofos, y especialmente los científicos sociales, incluso los más prácticos, tampoco son enteramente de este mundo. También ellos pueden ser expulsados de la república. O algo peor. En efecto, promediando esa peligrosa utopía de reingeniería social que es La República, Platón lamenta que su sueño nunca será realidad. Que, contra más perfecta sueña a su sociedad más se aleja su posibilidad: los filósofos —entendidos como los hombres más racionales y virtuosos, capaces de calcular en aras del interés común- nunca serán reyes, suspira Platón. El sabio que ha visto "el frenesí de la multitud y la insensatez en la conduc- 
ción de la vida pública...", haría mejor en apartarse de ella, y "alegrarse si al menos puede mantener sus manos limpias de corrupción"15.

Un efecto indirecto de que los filósofos no lleguen a reyes, será que los poetas no sean expulsados de la comunidad ideal (nuestro destino se une en esta metáfora...). Pero, si de todos modos quiere ser rey, mi intuición me dice que el filósofo público contemporáneo haría bien en ser además un poco poeta. O sea, haría bien en asomarse desde su razón a esta brecha; admitir la emoción como coadyuvante de la razón en los asuntos públicos; y emplear la imaginación poética para ponerse en el lugar de los gobernados como seres particulares y no abstracciones estadísticas.

Terminemos, entonces, recordando una última vez la pregunta de Platón, y sintetizando por fin la posible respuesta de Homero.

"Querido Homero, ¿podrías nombrar un país cualquiera que haya sido mejor gobernado gracias a tus esfuerzos?"

No, Platón, no puedo indicarte un país tan ideal. Pero lo que sí podría, quizás, es imaginar una sociedad más humana — por complejaque aquella que tú imaginaste en tu república ideal. Una sociedad donde los poetas y la poesía, por ejemplo, sean escuchados y leídos al intentar descubrir, acrecentar y vivir, la pluralidad del mundo.

Esa podría ser la respuesta de Homero, a la capciosa pregunta de Platón. Yo no estoy completamente convencido de ella. Pero me gusta como suena, lo que es propio de la irresponsable libertad de la poesía.

Por vuestra parte, si a los lectores filósofos no les gusta como suenan las respuestas que he sugerido, en nombre de Homero, siempre pueden coronarme con una vincha de lana, untarme de mirra la frente, y mandarme, con viento fresco, a las fronteras de otro país.

\section{REFERENCIAS}

Einstein, Albert y Leopold Infeld: The Evolution of Physics. Nueva York: Touchstone, 1938. Plato: The Republic. Oxford University Press, 1942.

Popper, Karl: The Logic of Scientific Discovery: Londres: Hutchinson, 1980.

Maquieira, Diego: "Ars Vitae". En Diego Maquieira, Los Sea Harriers. Santiago: Tajamar Editores.

Nussbaum, Martha: Poetic Justice: The Literary Imagination and Public Life. Beacon Press, 1995.

15 Plato, The Republic, pp. 199-200. 